\title{
Tecidos moles (não resistentes): como se fossilizam?
}

\author{
Silvia Regina Gobbo \\ Faculdade Ciências Exatas e da Natureza, Univ. \\ Metodista, Piracicaba, SP. \\ silviagobbo@yahoo.com.br; \\ Reinaldo J. Bertini \\ Depto. Geologia Aplicada, Inst. Geociências e \\ Ciências Exatas, Unesp Rio Claro, SP. \\ rbertini@rc.unesp.br
}

\begin{abstract}
SOFT TISSUES: HOW DO THEY FOSSILIZE? The preservation of soft tissue (not resistant) always draws attention, both for the quality of the fossils preserved, as for their rarity. This contribution makes extensive review of the subject and dispels some myths about the current fossilization of such materials, including anaerobiosis, quick burial. Additionally it also demonstrates the important role of replacement morphological structures by microbial colonies. Among the factors that influence the preservation of not resistant tissues are $\mathrm{pH}$, decomposition processes, rapid burial and rapid mineralization by carbonates or phosphates. It is possible to cite examples of sedimentary facies in which there is preservation of non resistant tissues as pyrobituminous shales, lithographic limestones, shales and diatomites. Note the role of microbial colonies, both in the form of microspheres, as those non-spherulitic. The three main myths that have been sought to be clarified in the article are: (1) the presence of oxygen, (2) the rapid burial and (3) the microbial colonies. Citation: Gobbo S.R., Bertini R.J. 2014. Tecidos moles (não resistentes): como se fossilizam? Terræ Didatica, 10(1):02-13. < http://www.ige.unicamp.br/terraedidatica/> .
\end{abstract}

KEYWORDS: Taphonomy, fossilization, Paleontology, necrolisis, fossil-lagerstätten

RESUMO A preservação de tecidos moles (não resistentes) desperta atenção pela qualidade dos fósseis preservados, e pela raridade. Este trabalho faz ampla revisão do assunto, desfaz alguns dos mitos correntes sobre fossilização destes materiais, como anaerobiose e soterramento rápido, bem como assinala a relevância do papel da replicagem de estruturas morfológicas por colônias microbianas. No âmbito dos fatores que influenciam a preservação de tecidos não resistentes estão pH, processos de decomposição, soterramento rápido e mineralização rápida por meio de carbonatos ou fosfatos. É possivel citar exemplos de fácies sedimentares nas quais há preservação de tecidos não resistentes, como os folhelhos pirobetuminosos, calcários litográficos, folhelhos e diatomitos. Destaca-se o papel das colônias microbianas, tanto na forma de microesferas, como aquelas não-esferuliticas. Os três mitos principais que se procurou desfazer no artigo são: (1) a presença de oxigênio; (2) o soterramento rápido e (3) as colônias microbianas.

PALAVRAS-CHAVE: Tafonomia, fossilização, Paleontologia, necrólise, fossil-lagerstätten 


\section{Introdução}

A raridade da presença de organismos de tecidos não resistentes, ou com poucas partes duras, no registro geológico, é um dos mais óbvios tendenciamentos resultantes dos processos de fossilização (Allison e Briggs, 1991). Estima-se que cerca de dois terços da biota de uma comunidade marinha normalmente não se fossiliza, por ser constituída apenas por animais de corpo mole (Lawrence 1968, Allison 1986, Allison e Briggs 1993), como, por exemplo, cnidários medusóides. Porém ocasionalmente ocorrem descobertas impressionantes de fósseis de animais sem tecidos resistentes, como os diversos espécimens de águas-vivas do Cambriano Médio da Formação Marjum em Utah (Fig. 1. Cartwright et al. 2007).

Assim que um organismo morre inicia-se o processo de decomposição, também chamado de necrólise. Consiste na decomposição dos tecidos não resistentes. A necrólise porém ocorre de maneira diferencial, alguns tecidos começam a se decompor em horas, outros em dias, portanto é preciso conhecer os tipos histológicos e seu potencial de preservação. Geralmente para o estudo da fossilização se definem os tecidos em dois tipos, não resistentes e resistentes. Mas o que são "tecidos moles" ou não resistentes?

Diversos autores, em contribuições relacionadas à Tafonomia, mencionam o termo soft tissues sem, entretanto, o definir (Allison e Briggs 1993, Briggs e Wilby 1996, Wilby et al. 1996, Wilby e Briggs 1997, Martill e Unwin 1997, Martill 1998, Hollingworth et al. 2001). Também são encontradas as variações para o vocábulo, tanto em inglês quanto em português como, por exemplo, partes moles (soft parts,) ou a referência a animais de corpo mole (soft bodies) como utiliza Allison (1988 a, b, c, d).

Utiliza-se o termo tecidos moles (soft tissues), ou não resistentes (Fig. 2), para designar estruturas histológicas não biomineralizadas, com a matriz extracelular rica em fibras de colágeno e elastina. Geralmente este vocábulo é utilizado para tecidos animais, assim são considerados como estruturas histológicas não resistentes os tecidos conjuntivo, epitelial, muscular,

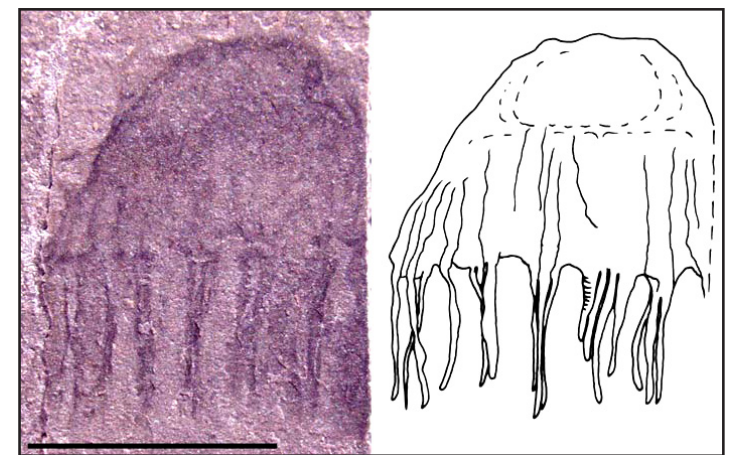

Figura 1. Imagem e desenho interpretativo de cnidário medusóide com tentáculos preservados, do Cambriano Médio da Formação Marjum, Utah. Escala 5 mm (Cartwright et al. 2007).

vascular, nervoso. Como exemplo tem-se peles, músculos, tendões, ligamentos, vasos sanguíneos, nervações, penas, pêlos, quitina.

Poucos autores utilizam o termo soft tissue para vegetais, entre eles Gastaldo et al. (2005) por exemplo, que preferem mencionar "(soft) tissue", entre parênteses, para tecido parenquimatoso vegetal, definido como sendo uma estrutura histológica pouco especializada. Desta maneira, podemos considerar que os tecidos vegetais relativamente pouco resistentes à preservação seriam caules, ramos novos e folhas das plantas vasculares, enquanto talos e frondes seriam os correspondentes para algas e outros vegetais não vascularizados. Esclareça-se que no desenvolver desta contribuição tecidos não resistentes se referem a estruturas histológicas de metazoários, ou animais multicelulares, entretanto,

\begin{tabular}{|c|c|c|}
\hline \multirow{2}{*}{$\begin{array}{l}\text { TIPO DE } \\
\text { ORGANISMOS }\end{array}$} & \multicolumn{2}{|c|}{ TECIDOS/ESTRUTURAS } \\
\hline & Não resistentes & Resistentes \\
\hline $\begin{array}{l}\text { Vegetais avasculares } \\
\text { e Talófytas }\end{array}$ & Talos e frondes. & $\begin{array}{l}\text { Girogonites(oogônios cal- } \\
\text { cificados de carófytas), } \\
\text { envoltório externo de } \\
\text { esporos }\end{array}$ \\
\hline $\begin{array}{l}\text { Vegetais vasculares } \\
\text { ou Traqueófytas }\end{array}$ & $\begin{array}{l}\text { Raízes e ramos novos, } \\
\text { folhas, flores, } \\
\text { parte carnosa de } \\
\text { frutos }\end{array}$ & $\begin{array}{l}\text { Envoltório externo de esporos } \\
\text { e pólens, lenho, cutículas } \\
\text { da epiderme. }\end{array}$ \\
\hline Invertebrados & $\begin{array}{l}\text { Tecidos conjuntivo, } \\
\text { epitelial, mus- } \\
\text { cular, vascular, } \\
\text { nervoso. }\end{array}$ & $\begin{array}{l}\text { Testas calcáreas, silicosasou } \\
\text { orgânicas, espiculas, con- } \\
\text { chas e outros esqueletos } \\
\text { carbonáceos (ex. corais e } \\
\text { equinodermos) e quitino- } \\
\text { sos (artrópodes). }\end{array}$ \\
\hline Vertebrados & $\begin{array}{l}\text { Tecidos conjuntivo, } \\
\text { epitelial, mus- } \\
\text { cular, vascular, } \\
\text { nervoso. }\end{array}$ & Dentes, escamas, ossos \\
\hline
\end{tabular}

Figura 2. Exemplos de estruturas e tecidos de diferentes organismos, de acordo com seu potencial de preservação. Os não resistentes tem menor potencial de preservação, enquanto estruturas e tecidos resistentes apresentam maior potencial de preservação. 
quando for de interesse, tecidos vegetais serão mencionados.

Acima definiram-se os tecidos não resistentes. Mas como classificar ossos, dentes e conchas? Estas são estruturas histológicas animais biomineralizadas, também chamadas de "partes duras", ou no inglês hard parts, que são relativamente resistentes à decomposição, por serem constituídas de minerais estáveis. Aqui serão chamadas de partes resistentes aquelas com maior potencial de preservação no registro fóssil.

Nos vegetais o potencial de preservação é maior para esporopolenina, composto orgânico envolvendo esporos e grãos de pólen, seguida da cutina, que compõe a camada cerosa recobrindo a superfície de caules, folhas e estruturas reprodutivas. Em seguida temos lignina e celulose, que compõem a porção lenhosa (Scott e Collinson 1983). A esporopolenina é considerada como um dos compostos orgânicos mais resistentes, podendo suportar grandes variações de $\mathrm{pH}$, incluindo

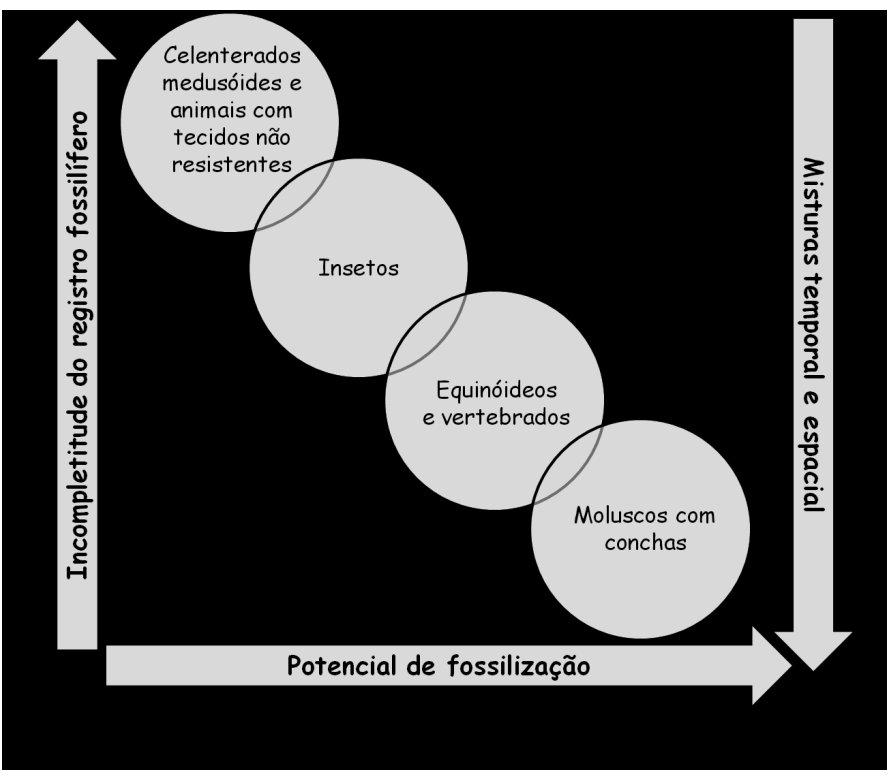

Figura 3. Modelo tafonômico recíproco (Kowalewski 1997). De acordo com este modelo, a presença de partes resistentes favorece a preservação, ou completitude do registro fóssil, por resistência à decomposição, mas ao mesmo tempo aumentam as possibilidades de mistura temporal e espacial (time averaging). Por outro lado animais sem partes resistentes tendem a ter baixa possibilidade de preservação, ou incompletitude do registro fóssil, porém com baixas possibilidades de mistura temporal e espacial.

ataques ácidos, e de temperatura, pois resiste até $320^{\circ} \mathrm{C}$, sem alterações na sua estrutura química (Ianuzzi e Vieira 2005). Porém os processos tafonômicos para preservação de vegetais são distintos, em relação a restos animais, e não serão tratados nesta contribuição.

A fossilização ocorre de maneira bastante diferenciada, dependendo da composição química original dos organismos, dos ambientes e até mesmo dos processos envolvidos. São conhecidos tanto fósseis de organismos originalmente constituídos apenas de tecidos não resistentes, como também se conhecem restos esqueléticos resistentes que não se preservam. Mas de maneira geral, considerando apenas a composição química original dos organismos, os modelos demonstram que a presença de partes resistentes favorece a fossilização (Fig. 3), conforme mencionado por diversos autores (Allison e Briggs 1991, Kowalevski 1997).

Os tecidos não resistentes, em geral, são muito susceptíveis à decomposição e excepcionalmente se preservam. Como pode ser observado no modelo tafonômico recíproco de Kowalewski (1997, Figura 3 ), quanto maior a presença de partes duras na biocenose original, maior a completitude do registro fóssil. Porém por outro lado, justamente por serem quimicamente estáveis e difíceis de decompor, as partes resistentes podem favorecer situações onde ocorrem misturas cronológica e espacial. Processos que causam mescla de fósseis de diferentes idades foram reunidos no que Walker e Bambach (1971) denominaram de mistura cronológica, e / ou temporal (time-averaging), que podemos definir como sendo a reunião de biocenoses de diferentes épocas em uma mesma camada estratigráfica.

Isto ocorre porque partes resistentes podem acumular-se antes do enterramento, ou mesmo ser re-exumadas e re-depositadas com outras biocenoses mais recentes (Flessa et al. 1993). Mas como pode ser observado no modelo tafonômico recíproco de Kowalewski (1997, Fig. 3), a preservação de tecidos não resistentes em geral está associada a baixas condições de mistura espacial e temporal. Por este motivo este assunto não será aprofundado nesta contribuição e sugere-se, para maiores detalhes sobre mistura cronológica, a leitura de $\mathrm{Holz}$ e Simões (2002).

A mistura espacial por sua vez ocorre quando carcaças são transportadas e depositadas fora do ambiente em que o organismo viveu. Como exemplo pode-se citar um organismo que vive em ambiente continental, mas é transportado por um rio e se deposita em ambiente marinho. Neste caso o transporte também age de maneira a selecionar 
os componentes bióticos, e em geral as partes não resistentes também são eliminadas neste processo. De acordo com o acima exposto, ao serem encontrados tecidos não resistentes preservados, têm-se também uma situação com baixo potencial de misturas cronológica e espacial.

$\mathrm{Na}$ eventualidade de misturas temporal ou espacial podemos dizer, de maneira sucinta, que a reunião de várias biocenoses diferentes, temporal ou espacialmente, em um mesmo momentum estratigráfico, dificulta ao paleobiológo desenvolver inferências paleoecológicas, sejam elas de interpretação paleoambiental ou mesmo de dinâmicas populacional ou de comunidades (Flessa et al. 1993). Mas também pode-se dizer que o contrário é verdadeiro, pois é em localidades onde se preservam organismos com partes não resistentes que existe maior resolução para interpretações paleoambientais e de comunidades.

Em algumas situações a decomposição parcial de tecidos não resistentes pode levar a análises taxonômicas e filogenéticas errôneas. Tais tendenciamentos ocorrem freqüentemente, por exemplo, com vegetais fósseis, na preservação de elementos isolados tais como folhas, troncos, frutos e polens, que com alguma frequência podem ser considerados espécies independentes e não espécimens (partes, estruturas) de uma mesma espécie.

Assim como ocorre em animais extintos, sem representantes modernos, especialmente aqueles de corpo mole, que apresentam elementos esqueletais isolados como, por exemplo, os conodontes. Estes só tiveram suas afinidades filogenéticas até certo ponto estabelecidas quando um exemplar excepcionalmente bem preservado, com detalhes anatômicos dos tecidos não resistentes, foi encontrado em depósitos carboníferos da Escócia (Briggs et al. 1983).

Realmente os tecidos não resistentes são mais raramente preservados no registro fóssil, quando comparados aos elementos biomineralizados ou partes duras. Porém quando encontramos organismos compostos de tecidos não resistentes preservados temos informações que vão desde a composição da comunidade, como no caso dos fósseis ediacaranos, que eram constituídos principalmente de organismos de corpo mole, que de outra forma talvez não fossem conhecidos, como podemos conhecer detalhes da anatomia, como órgãos internos.

Cefalópodos coleóideos, constituídos externamente de tecido não resistente, e internamente de uma concha em forma de pena, encontrados na localidade de Oxford Clay, na Inglaterra, apresentam uma preservação extraordinária. Muitos exemplares estavam tão delicadamente fossilizados, que estudos da anatomia interna foram feitos e indicaram a presença dos sacos de tinta, do manto muscular e dos tentáculos com seus ganchos e ventosas (Donovan e Crane 1992, Hollingworth et al. 2001). Um dos exemplares foi fossilizado segurando um peixe com seus tentáculos, permitindo assim conhecer detalhes comportamentais (Hollingworth et al. 2001). Outros casos, como os peixes da Chapada do Araripe, Nordeste do Brasil, também apresentam uma preservação tão impressionante que se pode estudar a estrutura dos tecidos a nível sub-celular (Martill 1990).

Assim retornamos à pergunta: como se preservam tecidos moles? Para responder a esta questão temos que recorrer à Tafonomia (do grego taphos, sepultamento; nomos, leis), ciência que investiga os processos que ocorrem da morte do organismo até a formação do fóssil e sua exumação. Tafonomia é um termo criado por Efremov (1940), que assim a definiu: "estudo da transição de restos orgânicos da biosfera para a litosfera".

Além de estudos tafonômicos são utilizados também os princípios da Actuopaleontologia, também denominada Paleontologia Atualística, ramo da Paleobiologia desenvolvido por Richter (1928), que se ocupa do estudo de vida e morte de organismos atuais em seus habitats, incluindo processos post-mortem, para extrapolar estas informações na interpretação de registros fósseis (Holz e Simões 2002).

Despertam grande interesse de estudo, quando fossilizados, especialmente os organismos constituídos apenas de tecidos não resistentes, sem conchas e esqueletos, pois representam importante parcela da biocenose original, geralmente eliminada por tendenciamentos tafonômicos. Como vimos acima, a principal tendência tafonômica é justamente preservar organismos que possuem partes duras, eliminando aqueles constituídos apenas de tecidos moles.

O transporte é um dos responsáveis por esta tendência, pois animais de tecidos não resistentes podem se desintegrar no transporte, devido à ação de agentes tais como água, vento e gelo. Além disto, estes organismos têm uma necrólise mais rápida, dificilmente se preservando. Somente partes duras como conchas, dentes e ossos permanecem íntegros à ação destrutiva do transporte e por isto consti- 
tuem a maior parte dos fósseis encontrados. Então encontrar um jazimento fóssil, também chamado de orictocenose, com organismos de tecidos não resistentes preservados, é como abrir uma janela para o passado, pois sabemos que ambientes preservando organismos de corpo mole tem menores misturas cronológica e espacial, de acordo com o modelo da Figura 3.

Ambientes que permitem uma excepcional preservação dão origem aos chamados fossil-lagerstätten (Seilacher 1970). Lagerstätte apresenta o plural Lagerstätten, derivando das palavras em alemão lager e stätte, que significam literalmente "lugar de estoque”. Não existe um termo correspondente em português, e a definição mais completa é "um corpo rochoso contendo um número incomum de informações paleontológicas, devido à qualidade e / ou quantidade da preservação". O mesmo autor diferencia os fossil-lagerstätten em dois tipos: Konzentrat-Lagerstätten e Konservat-Lagerstätten.

Konzentrat-Lagerstätten são assim definidos por apresentarem concentração incomum na quantidade de fósseis, em geral de elementos desarticulados com partes resistentes, formando verdadeiras bone-beds ou shell-beds. Este tipo representa, em geral, depósito com grandes possibilidades de misturas temporal e espacial, seja por baixas taxas de sedimentação e / ou retrabalhamento.

Konservat-Lagerstätten são depósitos excepcionais pela qualidade incomum na preservação dos fósseis (Konservat, termo alemão para qualidade, conservação), quando tecidos não resistentes se preservam, seja na forma de moldes, impressões ou mesmo por replicagem, como será abordado mais à frente. Estes depósitos são muito importantes por representarem literalmente "uma janela para o passado", pois exibem ocorrências dos organismos sem partes duras que raramente se preservam. Assim espera-se, nestes casos, que a estrutura da comunidade esteja mais bem representada, permitindo estudos paleoecológicos mais acurados.

Este tipo de lagerstätte requer condições ambientais específicas para preservação de partes moles. Se pretende-se compreender a fossilização de estruturas histológicas não resistentes temos que começar por definir os paleoambientes favoráveis a este tipo de preservação. São chamados de "ambientes sedimentares estéreis", definidos como aqueles "em que as condições ambientais excedem as tolerâncias ecológicas de bactérias decompositoras" (Allison e Briggs 1991). Entre os exemplos mais conhecidos temos âmbar, turfeiras, permafrost, areias movediças, cavernas secas, evaporitos (depósitos de sal).

São conhecidos por serem sistemas antissépticos, pela presença de sal, ácidos húmicos ou resinas, ou ambientes de condições extremas, secos ou frios, mas onde necessariamente a água encontra-se indisponível. Estes paleoambientes têm produzido inúmeros exemplos de fósseis com tecidos não resistentes preservados, como as múmias das turfeiras de Sphagnum do Norte da Europa, que preservam desde pele até órgãos internos, devido ao ambiente constituído de águas ácidas, baixas temperaturas e depletados em oxigênio. Porém, neste caso em particular, os ácidos húmicos dissolvem o fosfato de cálcio dos ossos preservando apenas os tecidos moles (Pringle 2002).

Mas existe outro tipo de fossilização que permite uma preservação ainda mais excepcional de tecidos não resistentes, que é chamada de "replicagem por minerais autigênicos", que são formados durante a sedimentação ou na fase de diagênese precoce, particularmente fosfato de cálcio. Neste caso, tecidos moles com detalhes musculares, nervos, vasos sanguíneos, são preservados em sua forma tridimensional. Este é o caso, por exemplo, da Formação Santana (Bacia do Araripe / Brasil - Fig. 4), que será enfatizado neste trabalho.

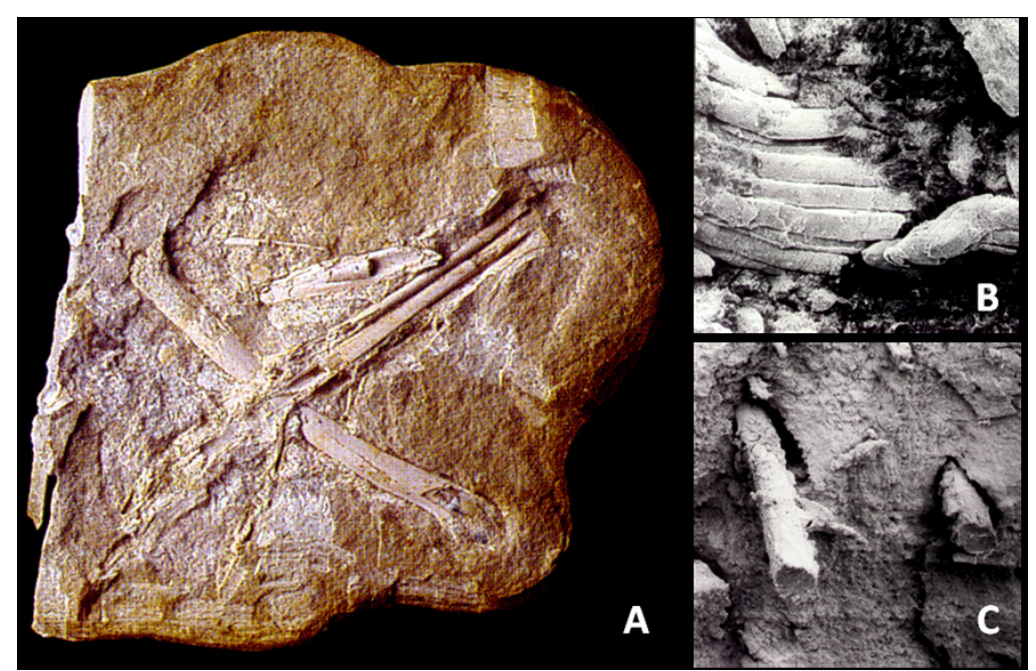

Figura 4. Santanaraptor placidus. A - Nódulo calcário com membro posterior que apresenta tecidos não resistentes preservados. B-C: Detalhes do tecido mole preservado de Santanaraptor placidus; B - fibras musculares. C - vasos sanguíneos (Kellner et al. 1999). 


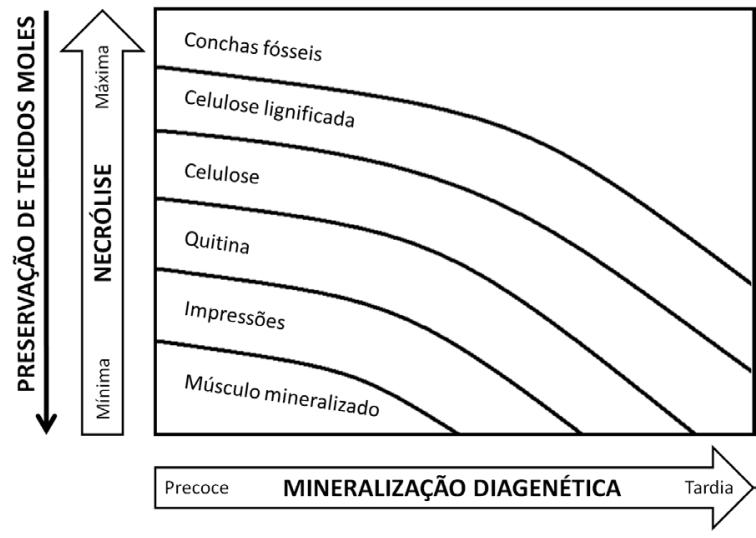

Figura 5. Relações entre decomposição, mineralização e preservação. Observa-se que a preservação de tecidos não resistentes se deve a uma associação de dois fatores: um mínimo de decomposição e uma mineralização diagenética precoce (modificado de Martin 1999).

Pela seqüência esperada da decomposição de um organismo (que pode ser visualizada na Figura 5) os tecidos não resistentes são os primeiros a serem afetados, a não ser que algum evento interrompa a decomposição e permita uma mineralização diagenética precoce. Por mineralização diagenética consideramos a precipitação de minerais durante o processo de diagênese.

Diagênese é o conjunto de processos físicos (compactação) e químicos (dissolução, cimentação, neoformação de minerais) que atuam sobre o sedimento, desde sua deposição até litificação e reexposição à superfície (Holz e Simões 2002). Mas como isto acontece?

\section{Fatores que influenciam a preservação de tecidos não resistentes}

\section{Decomposição}

A decomposição de tecidos não resistentes, também chamada de necrólise, é em geral rápida e ocorre logo após a morte do organismo. A necrólise é causada por animais saprófagos e microorganismos, a partir de processos físicos e químicos. Estes podem ocorrer em ambientes aeróbicos e anaeróbicos, respectivamente em presença ou ausência de oxigênio livre.

Normalmente se espera que a decomposição biológica seja alta em ambientes aeróbicos e reduzida em anaeróbicos, mas Allison e Briggs (1991) têm uma perspectiva diversa sobre este aspecto. Segundo estes autores a proposta de que o ambiente anóxico é um inibidor intrínseco da decomposição é equivocada, e que sozinha é insuficiente para promover a preservação de partes não resistentes. Allison (1988a), em experimentos atualísticos de decomposição em ambiente anóxico, considera que praticamente não existem diferenças nas taxas de decomposições aeróbica e anaeróbica. Porém a condição de anoxia do meio é importante, pois deve inibir necrofagia e bioturbação, o que facilita preservação de partes duras articuladas, mesmo quando não há fossilização de tecidos moles. Apesar dos autores citados utilizarem o termo anóxico, devemos aqui considerar preferencialmente uma condição de desoxia, pois anoxia seria ausência total de oxigênio livre, o que nem sempre ocorre.

\section{Soterramento rápido}

Soterramento rápido é sempre considerado, pelos autores em geral, como uma variável importante para uma preservação excepcional. No caso específico de preservação de tecidos não resistentes, Allison e Briggs (1991) consideram este fator como significativo, principalmente se a cobertura de sedimentos for suficiente para proteger a carcaça de necrofagia e distúrbios produzidos por animais da infauna. Como explicitado acima estes autores consideram que a condição de anoxia, promovida pelo soterramento rápido, tem uma influência desprezível na preservação de tecidos moles em si. Tradicionalmente anoxia e soterramento rápido eram considerados como os principais requisitos para a preservação de tecidos não resistentes e a formação de Konservat-Lagerstätten, mas hoje novas variáveis são consideradas. De acordo com Allison (1988a) são fatores importantes somente por promover uma mineralização diagenética precoce.

\section{Mineralização rápida}

Embora o soterramento rápido seja importante para impedir a ação de necrófagos, não impede a decomposição anaeróbica. O que realmente passa a ser um fator importante na preservação de tecidos não resistentes é a prevenção da perda de informação causada pela decomposição. Isto normalmente ocorre através da replicação da morfologia das estruturas histológicas moles (músculos, vasos sanguíneos, etc.) através de mineralização diagenética precoce, por pirita, carbonatos e fosfatos (Fig. 6).

A natureza da mineralização diagenética precoce depende da química da água (salinidade, 


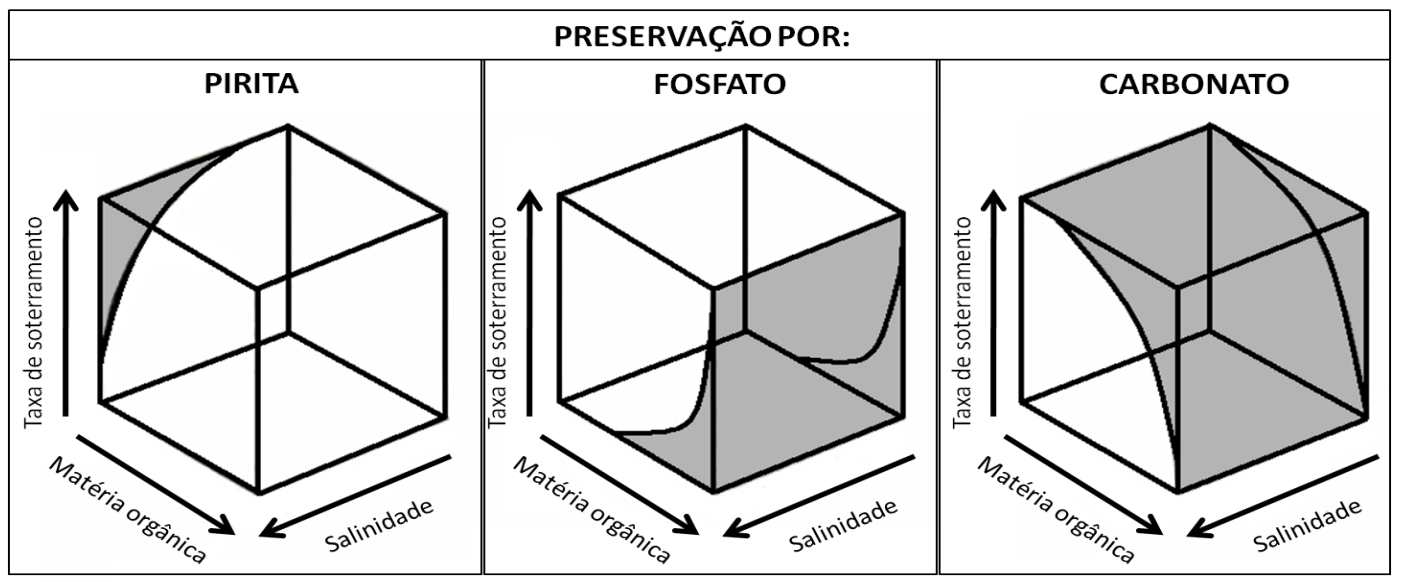

Figura 6. Parâmetros deposicionais requeridos para preservação de tecidos não resistentes por pirita, fosfato ou carbonato. A piritização diagenética precoce requer soterramento rápido (algumas vezes catastrófico), baixo conteúdo de matéria orgânica e a presença de sulfatos. Por sua vez a fosfatização diagenética precoce depende de baixas taxas de sedimentação, mas alto conteúdo de matéria orgânica, embora a mineralogia varie com a salinidade. A preservação por carbonatos requer soterramento rápido (talvez catastrófico), sedimento rico em matéria orgânica, embora a mineralogia possa variar com a salinidade (redesenhado a partir de Martin 1999).

condições redutoras) e disponibilidade de matéria orgânica reativa. Como se pode observar na Figura 6, o soterramento rápido nem sempre é condição sine qua non para preservação de tecidos não resistentes. A fosfatização, por exemplo, requer baixas taxas de sedimentação.

\subsection{Folhelhos pirobetuminosos}

Estes depósitos são característicos de ambientes anóxicos. A atividade biológica é muito reduzida na interface água / sedimento. Esta é a origem de acúmulos fósseis famosos, como por exemplo, Holzmaden, do Toarciano (andar final do Eo-Jurássico) e Messel (Eoceno), ambas localidades situadas na Alemanha. Como previamente mencionado acima no texto (Kellner et al. 1999), no Brasil podemos mencionar os membros Crato e Romualdo da Formação Santana, Aptiano / Albiano do Ceará, embora no segundo deles a preservação ocorra mais especificamente no âmbito de concreções calcárias, portanto diferentemente daquilo que ocorre em Holzmaden ou Messel. Todavia não sendo um verdadeiro lagerstätten, os proganossauros da Formação Irati, Eo-Permiano da Bacia do Paraná, também exibem algumas preservações de tecidos não resistentes, como membranas interdigitais, por exemplo (Rosler 1974, Rosler e Tatizana 1985, Raimundo-Silva et al. 1997).

\subsection{Carbonatos}

Mineralização diagenética precoce por carbonatos é o processo mais freqüente de preservação de tecidos não resistentes. A decomposição de carbono orgânico, sob condições anaeróbicas, produz íons de bicarbonatos, que podem se combinar com cálcio ou ferro. Carbonato de cálcio se forma preferencialmente em condições marinhas, enquanto em ambientes de águas continentais o ferro pode gerar concentrações suficientes para precipitar siderita.

\subsection{Fosfatos}

A mais espetacular preservação de tecidos não resistentes, em termos de qualidade da informação morfológica, ocorre pela mineralização diagenética precoce de fosfatos. Mas para a formação de fosfatos autigênicos é necessário que a concentração de fosfatos exceda muito aquela de carbonatos. Existem casos em que a fosfatização tem como fonte o fósforo presente na própria carcaça, ou seja, disponível no microambiente pela decomposição de outras partes do próprio organismo (Wilby e White 1995). Isto ocorre em fosfatizações um tanto limitadas, que acontece de maneira desigual, fossilizando bem algumas partes do organismo enquanto outras não.

Fosfatizações mais extensas requerem uma fonte externa de fósforo (Wilby 1993), ou seja, no ambiente externo, na coluna de água, o fósforo deve estar saturado, ou pelo menos em grande disponibilidade. Esta é uma questão interessante, 
e existem evidências de que, ao longo do tempo geológico, esta disponibilidade de fósforo nos oceanos diminuiu.

Donoghue et al. (2006) revisam as ocorrências de embriões fosfatizados de Neo-Proterozóico até Eo-Ordoviciano, incluindo Doushantuo e Chengjiang na China, Burgess no Canadá, Orsten na Suécia. São comparáveis em preservação, e denominadas de fosfatização tipo Orsten, um tipo específico de replicagem por fosfato de cálcio a partir de biofilmes. Este tipo de fossilização parece ter uma "janela" de tempo restrita a este intervalo de tempo, entre Neo-Proterozóico e Eo-Ordoviciano, e representaria, segundo estes autores, um momento onde havia mais fósforo disponível nos oceanos, em relação a períodos geológicos posteriores. Após o Ordoviciano a replicagem do tipo Orsten não volta a ocorrer.

Coincidentemente o fim da preservação Orsten está também relacionado ao aumento de bioturbações, que dificultariam o desenvolvimento dos biofilmes microbianos. Esta fase é chamada de "agronomic revolution" e representa o aparecimento da infauna de ambientes desóxicos, cuja atividade oxigenaria o substrato (Sepkoski 1982).

Porém nem todo tipo de replicação por fosfatização é do tipo Orsten, pois outros tipos de replicagem por fosfatos são registradas na literatura, como nos vertebrados da Chapada do Araripe (Martill 1990). Mas parece que nestes casos a disponibilidade de fósforo é relacionada a um ambiente específico, ou então a um microambiente em torno da carcaça em decomposição, como mencionado anteriormente.

Allison (1988b) comenta que é necessário um aumento de $\mathrm{pH}$ para ocorrer a precipitação de fosfatos, e que o microambiente em volta dos animais proteináceos em decomposição geralmente apresenta $\mathrm{pH}$ alto (condições alcalinas). Esta concentração requer altos aportes de material orgânico, e taxas muito baixas de sedimentação. Áreas onde o nível do mar está subindo, áreas transgressivas, portanto, podem ser importantes locais para formação de fosfatos. Fontes de fosfatos inorgânicos, por exemplo, atividade vulcânica, pode ser importante em alguns casos.

\section{4. $\mathrm{pH}$}

O pH da água não é um fator decisivo na preservação de tecidos não resistentes (soft tissues) por "replicagem", conforme abordado aqui. Briggs e Wilby (1996) enfatizam que na preservação de animais de corpo mole por mineralização, o papel do $\mathrm{pH}$ é muito localizado, no microambiente em torno da carcaça em início de decomposição. Nestes casos ocorre uma acidificação inicial, produzida por metabolismo microbiano, tais como $\mathrm{CO}_{2} \mathrm{e}$ $\mathrm{H}_{2} \mathrm{~S}$. Esta queda do $\mathrm{pH}$, em ambientes saturados por $\mathrm{CaCO}_{3}$, facilita a precipitação de apatita. Esta situação ocorre quando biofilmes microbianos crescem sobre as carcaças, gerando um microambiente "fechado" (Martill 1988, Wilby et al. 1996, Briggs 2003 a, b). Em artrópodos o próprio exoesqueleto pode favorecer este tipo de reação no interior dos restos do organismo, conforme sugere Briggs e Kear (1994). A fonte de fósforo requerida para a replicagem pode vir da própria decomposição de outras partes da carcaça, ou de uma fonte externa no ambiente (Wilby e Briggs 1997).

\section{Exemplos de localidades e fácies sedimentares com tecidos não resistentes preservados}

De acordo com Gall (1990), algumas fácies sedimentares são mais favoráveis à fossilização de tecidos não resistentes. Representam a diversidade de situações paleoambientais propícias a cada tipo de fossilização. Entre elas destacam-se as que seguem.

\section{Folhelhos betuminosos}

Depósitos de folhelhos betuminosos são característicos de ambientes anóxicos. A atividade biológica é muito reduzida na interface água/ sedimento. Esta é a origem de acúmulos fósseis famosos, como por exemplo, Holzmaden, do Toarciano (andar final do Eo-Jurássico) e Messel (Eoceno), ambas localidades situadas na Alemanha. Como previamente mencionado acima no texto (Kellner et al. 1999), no Brasil podemos mencionar os membros Crato e Romualdo da Formação Santana, Aptiano / Albiano do Ceará, embora no segundo deles a preservação ocorra mais especificamente no âmbito de concreções calcárias, portanto diferentemente daquilo que ocorre em Holzmaden ou Messel. Todavia não sendo um verdadeiro lagerstätten, os proganossauros da Formação Irati, Eo-Permiano da Bacia do Paraná, também exibem algumas preservações de tecidos não resistentes, como membranas interdigitais, por exemplo (Rosler 1974, Rosler e 
Tatizana 1985, Raimundo-Silva et al. 1997).

\section{Calcários litográficos}

São conhecidos pela qualidade de seus fósseis, com preservações excepcionais, incluindo inúmeros exemplos de tecidos não resistentes. Entre os depósitos mais conhecidos estão Solnhofen, Neo-Jurássico da Alemanha; Montsech, Eo-Cretáceo da Espanha; Membro Crato da Formação Santana, Aptiano / Albiano do Brasil; Cerin, Jurássico da França; Monte Bolca, Terciário da Itália.

\section{Folhelhos e diatomitos}

Rochas argilosas, por serem granulometricamente finas, permitem boa fossilização de organismos com tecidos não resistentes. Como exemplo pode se citar os folhelhos verdes de Grès à Voltzia, Bundsandsteino superior, Eo-Triássico da França. Varves lacustres, com a preservação de organismos

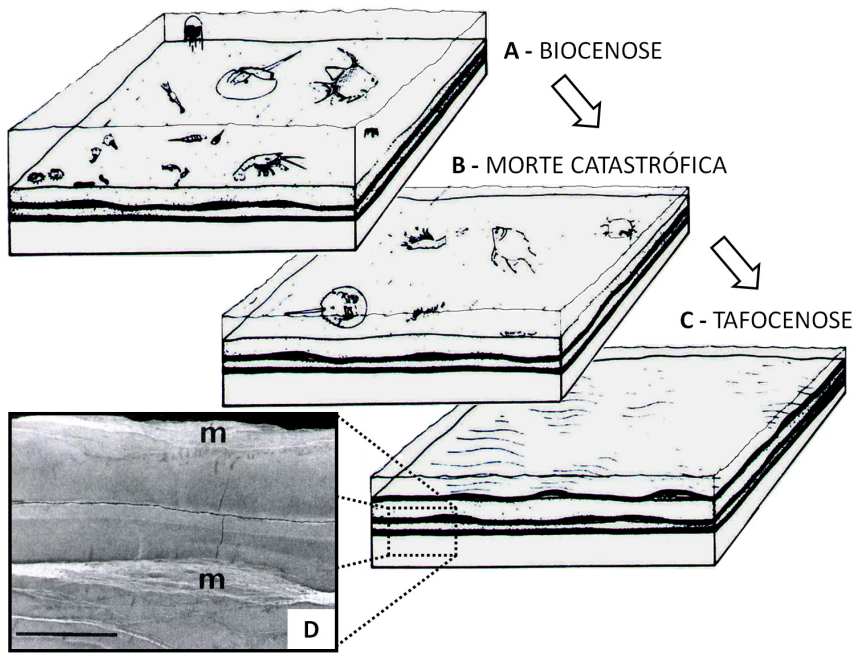

Figura 7. Esquema da formação de colônias microbianas em sedimentos. A - biocenose, B - mortalidade em massa, C - formação de tapetes microbianos em camadas ricas em matéria orgânica (modificado de Gall 1990). D - Colônias microbianas (indicadas pela letra $\mathrm{m}$ ) fossilizadas na localidade de Cerin (França). As colônias ocorrem no topo de pacotes escuros de sedimentos carbonáticos (escala $1 \mathrm{~cm}$ - Wilby et al. 1996)

com estruturas histológicas moles, estão associadas a diatomitos miocênicos na Anatólia.

\section{0 papel das colônias microbianas}

A fossilização de tecidos não resistentes não depende apenas de características litológicas ou da natureza do paleoambiente. Processos microbianos são geralmente necessários para induzir a anoxia das águas de fundo e intersticiais, levando à precipitação de minerais diagenéticos precocemente. Além disto, os microorganismos podem desempenhar papéis mais diretos na fossilização.

Biofilmes microbianos, formados por bactérias ou algas, se formam no topo do substrato ou na coluna de água, podendo também revestir restos orgânicos. Muitos autores (Seilacher et al. 1985, Allison 1988a e b, Gall 1990, Wilby 1993, Wilby e White 1995, Wilby et al. 1996, Harding e Chant 2000, apenas para citar alguns dos trabalhos mais conhecidos) apontam a intervenção de massas algálicas e colônias microbianas, que proliferam sobre a carcaça, promovendo inicialmente fosfogênese através da degradação da parte orgânica, posteriormente formando uma barreira, selando as reações químicas que estão ocorrendo na carcaça, impedindo que este fósforo liberado dos tecidos pela necrólise se difunda pela coluna de água, protegendo a carcaça contra degradações física e química.

Allison (1988b), por exemplo, cita que bacté-

rias podem precipitar apatita em células, quando as concentrações de fosfatos no meio são altas.

Comunidades bentônicas microbianas, de acordo com Gall (1990), são associações complexas de procariontes fotossintéticos como cyanobactérias, diversas algas unicelulares e microorganismos quimiotróficos. As formas esféricas e filamentosas são representativas destes grupos microbianos de fundo, bem como a produção de mucilagem abundante, que cresce na superfície dos sedimentos, ou dos tapetes microbianos (Fig. 7).

Nos ambientes atuais, as associações de microorganismos se desenvolvem em condições extremas, ou onde a competição biótica é reduzida. Os microorganismos têm crescimento muito rápido e abundante produção de mucilagem, que isola a carcaça do restante do meio. Além desta ação mecânica, os microorganismos promovem a precipitação de carbonatos que fixam as morfologias das estruturas. A proliferação destes microorganismos é limitada a ambientes bem específicos, em geral apresentando estratificação da coluna de água, onde o fundo é anóxico e hostil a outros animais, mas é propício ao desenvolvimento destas colônias (Gall 1990).

Acredita-se ainda que as colônias microbianas impedem as carcaças de flutuar, as protegendo de necrófagos e intemperismos vários (Wilby et al. 1996). Alem disto podem funcionar como pseu- 
domorfos (réplicas) das partes não resistentes, como demonstra Wilby et al. (op. cit.), ao descrever uma associação fóssil entre altas concentrações de fosfatos, colônias microbianas e tecidos moles, fossilizados em calcários jurássicos de Cerin, na França. A fosfatização de tecidos não resistentes, por apatita autigênica ou hidroxiapatita, permite a preservação com alta fidelidade de detalhes (Martill 1990, Briggs et al. 1983, Wilby 1993).

Wilby (1993) descreve duas fábricas, ou dois tipos de substituição, dos tecidos não resistentes originais:

\subsection{Microesferas}

Microesferas possuem cerca de $1 \mu \mathrm{m}$ de diâmetro e são geralmente esféricas ou subesféricas na forma. São geralmente compostas por "microcristais" equi-dimensionais, que variam de 50 a $100 \mathrm{~nm}$ de comprimento, que mostram orientação inteiramente randômica (Fig. 8A), ou de irradiação com ou sem um orifício central (Fig. 8B). Tecidos não resistentes pseudomorfizados por uma coleção destes cristais agregados geralmente mostram uma resolução subcelular, e podem se assemelhar muito a tecidos biomineralizados in vivo (Pautard 1981, Frasca 1981 apud Wilby 1993).

\subsection{Microcristais não-esferulíticos}

Neste caso tecidos não resistentes são substituídos ou cobertos preferencialmente por "microcristais" de aparência granular, que não estão agregados em cachos. As dimensões máximas dos cristais estão entre 20 e $100 \mathrm{~nm}$. Desde que estes "microcristais" sejam muito pequenos, e orientados espacialmente de acordo com o substrato biológico original, serão capazes de mostrar detalhes macromoleculares (Fig. 9). A comparação de tecidos substituídos por "microcristais" individuais, em relação com os substituídos por microesferas, claramente ilustra a diferença na informação que as duas tramas são capazes de preservar. Esta comparação, onde podemos observar com clareza a diferença na qualidade da informação de replicagem, pode ser vista na Figura 10.

\section{Considerações Finais}

A formação de tecidos não resistentes depende de diferentes fatores, mas os trabalhos citados ao longo deste artigo desmontam alguns dos antigos mitos sobre fossilização.

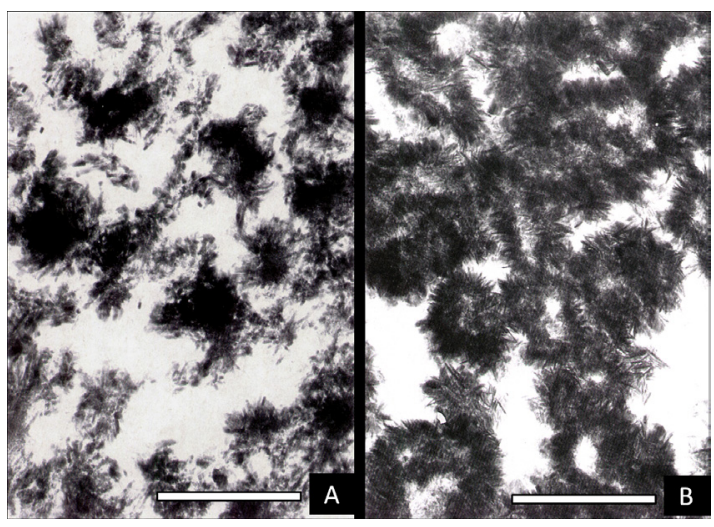

Figura 8. Aspectos de microsferas. 8A - Microesferas compostas de "microcristais" randomicamente orientados (escala 100 nm), Fm. Santana. 8B Microesferas compostas de "microcristais" radiados e com orifícios centrais (escala $500 \mathrm{~nm}$ ), Fm. Santana (Wilby 1993)

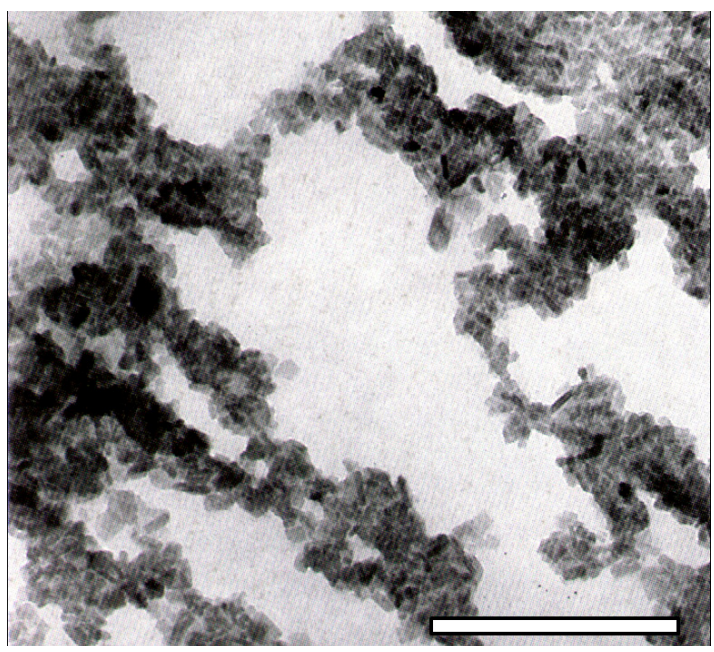

Figura 9. Tecido conectivo substituído por trama de cristais não esferulíticos, Fm. Santana (escala 50 nm) (Wilby 1993)

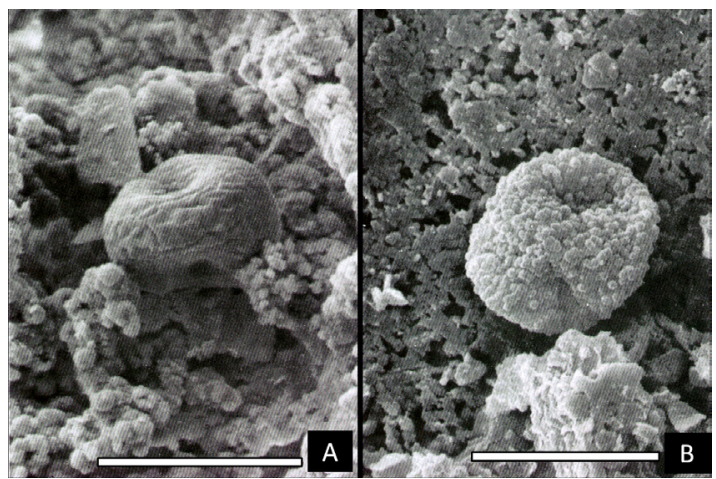

Figura 10. Células sanguíneas preservadas por diferentes fábricas. A - Célula sanguínea substituída por fábrica de cristais não-esferulíticos, Fm. Santana (escala 10 um). B - Célula sanguínea substituída por fábrica de cristais micro-esferulíticos, Fm. Santana (escala 10 um) (Wilby 1993) 


\section{Mito 1. Presença de oxigênio}

"O ambiente aeróbico promove decomposição e o anaeróbico a inibe." Como vimos acima ambientes aeróbicos promovem decomposição tanto quanto anaeróbicos, mas a anoxia, ou pelo menos desoxia do meio, deve inibir necrofagia e bioturbação, o que facilita a preservação de partes duras articuladas, mesmo quando não há preservação de tecidos não resistentes.

\section{Mito 2. Soterramento rápido}

Realmente o soterramento rápido promove a desoxia ou até a anoxia no meio, o que, como citado no mito anterior, inibe necrofagia e bioturbação, mas não impede decomposição da matéria orgânica em si.

\section{Mito 3. Colônias microbianas}

Colônias microbianas não são mencionadas como sendo importantes na formação de depósitos com tecidos não resistentes preservados mas, como vimos ao longo do trabalho, esteiras microbianas desenvolvem-se em ambiente anóxico / desóxico, impedindo as carcaças de flutuarem, promovendo a fosfogênese, e "replicando" as estruturas morfológicas para formar pseudomorfos.

\section{Agradecimentos}

Os autores agradecem a Caetano Julio Neto pelo auxílio na confecção das figuras.

\section{Referências bibliográficas}

Allison P.A. 1986. Soft-bodied animals in the fossil record. The role of decay in fragmentation during transport. Geology, 14:979-981.

Allison P.A. 1988a. The role of anoxia in the decay and mineralization of proteinaceous macro-fossils. Paleobiology, 14:139-154.

Allison P.A. 1988b. Phosphatized soft-bodied squids from the Jurassic Oxford Clay. Lethaia, 21:403410.

Allison P.A. 1988c. Taphonomy of the Eocene London clay biota. Paleontology, 31:1079-1100.

Allison P.A. 1988d. Konservat-Lagerstätten: cause and classification. Paleobiology, 14:331-344.

Allison P.A., Briggs D.E.G. 1991. Taphonomy. Releasing the locked in the fossil record. New York. Plenum Press. 560p.

Allison P.A., Briggs D.E.G. 1993. Exceptional fossil record. Distribution of soft-tissue preservation through the Phanerozoic. Geology, 21:527-530.

Briggs D.E.G., Wilby P.R. 1996. The role of the calcium-carbonate calcium-phosphate switch in the mineralization of soft-bodied fossils. J. Geol. Soc., 153:665-668.

Briggs D.E.G. 2003a. The role of biofilms in the fossilization of non-biomineralized tissues. In: W.E. Krumbein, D.M. Paterson, e G.A. Zarvarzin. eds. 2003. Fossil and recent biofilms: a natural history of life on Earth Dordrecht, Kluwer Acad. Publ. P. 281-290.

Briggs D.E.G. 2003b. The role of decay and mineralization in the preservation of soft-bodied fossils. Annual Review Earth Planetary Sciences, 31:275-301.

Briggs D.E.G., Clarkson E.N.K., Aldridge R.J. 1983. The conodont animal. Lethaia, 16:1-14.

Briggs D.E.G., Kear A.J. 1994. Decay and mineralization of shrimps. Palaios, 9:431-456.

Cartwright P., Halgedahl S.L., Hendricks J.R., Jarrard R.D., Marques A.C., Collins A.G., Lieberman B.S. 2007. Exceptionally preserved jellyfishes from the Middle Cambrian. PLoS ONE 2: e1121.

Donovan D.T., Crane, M.D. 1992. The type material of the Jurassic cephalopod Belemnoteuthis. Palaeontology, 35:273-296.

Donoghue P.C.J., Kouchinsky A., Waloszek D., Bengtson S., Dong X.-P., Val'kov A.K., Cunningham J.A., Repetski J.E. 2006. Fossilized embryos are widespread but the record is temporally and taxonomically biased. Evolution \& Development, 8:232-238.

Efremov I. 1940. Taphonomy: a new branch of Paleontology. Pan-American Geologist, 74:81-93.

Flessa K.W., Cutler A.H., Meldahl K.H. 1993. Time and Taphonomy. Quantitative estimates of time-averaging and stratigraphic disorder in a shallow marine habitat. Paleobiology, 19:266-286.

Gastaldo R.A., Adendorff R., Bamford M.K., Labandeira C., Neveling J., Sims H.J. 2005. Taphonomic trends of macrofloral assemblages across the Permian-Triassic boundary, Karoo Basin, South Africa. Palaios, 20:478-497.

Gall J.C. 1990. Les voiles microbiens. Lur contribution à la fossilisation des organismes au corps mou. Lethaia, 23:21-28.

Harding I.C., Chant L.C. 2000. Self-sedimented diatom mats as agents of exceptional preservation in the Oligocene Florissant lake beds, Colorado, United States. Geology, 28:195-198.

Hollingworth N., Wilby P., Hilton J. 2001. Callovian calamari. A case of exceptional preservation. Geoscientist, 11:4-8.

Holz M., Simões M.G. 2002. Elementos fundamentais de Tafonomia. Porto Alegre: Ed. UFRGS, 231p.

Ianuzzi R., Carlos E.L. 2005. Paleobotânica. Porto Alegre, Editora da UFRS, 167p.

Kellner A.W.A., Schwanke C., Campos D.A. 1999. 
O Brasil no tempo dos dinossauros. Rio de Janeiro. Museu Nacional. 60p.

Kowalewski M. 1997. The reciprocal taphonomic model. Lethaia, 30:86-88.

Lawrence D.R. 1968. Taphonomy and information losses in fossil communities. Geol. Soc. Am. Bull., 79:1315-1330.

Martill D.M. 1988. Preservation of fish in the Cretaceous Santana Formation of Brazil. Palaeontology, 31:1-18.

Martill D.M. 1998. Soft tissues in pterosaurs. Transactions of the Leicester Literary E Philosophical Society, 92:25-26.

Martill D.M, Unwin D.M. 1997. Small spheres in fossil bones: blood corpuscles or diagenetic products? Paleontology, 40:619-624.

Martin R.E. 1999. Taphonomy. A process approach. Cambridge: Cambridge Univ. Press. 508p.

Pringle H. 2002. O mundo das múmias. Rio de Janeiro: Ediouro. 292p.

Raimundo-Silva, R; Ferigolo, J. \& Sedor, F.A. 1997. Primeiras evidências de conteúdo digestivo em Brazilosaurus sanpauloensis (Reptilia, Mesosauridae) da Formação Irati, Bacia do Paraná. Boletim Resumos $15^{\circ}$ Congresso Brasileiro Paleontologia. p. 85.

Richter R. 1928. Aktuapaläontologie und Paläobiologie, eine Abgrenzung. Senckenbergiana, 10:285292.

Rosler O. 1974. Aspectos tegumentários de Mesosauridae (Reptilia) do Permiano, Formação Irati, Estado de São Paulo. Ciência e Cultura, 26:190-191.

Rosler O., Tatizana G. 1985. As membranas natatórias em Stereosternum tumidum. DNPM, Colet. Trab. Paleontológicos, 27:129-131.
Seilacher A. 1970. Begriff und Bedeutung der FossilLagerstätten. Neues Jahrbuch für Geologie und $\mathrm{Pa}$ laontologie, Heft 1:34-39

Seilacher A., Reif W.-E., Westphal F. 1985. Sedimentological, ecological and temporal patterns of Fossil-Lagerstätten. Philosophical Transactions of the Royal Society of London, B 311:5-23.

Sepkoski J.J. 1982. Flat-pebble conglomerates, storm deposits, and the Cambrian bottom fauna. In $\mathrm{G}$. Einsele, A. Seilacher (editors). Cyclic and Event Stratification. Springer, Berlin. 371-385.

Scott, A., Collinson M. 1983. Investigating fossil plant beds. Part 2: methods of paleoenvironmental analisys and modeling and suggestions for experimental work. Geological Teaching, 8:12-26.

Walker K.R., Bambach R.K., 1971. The significance of fossil assemblages from fine-grained sediments: time-averaged communities. Geol. Soc. Am. Abstracts with Program 3: 783-784.

Wilby P.R. 1993. The role of organic matrices in post-mortem phosphatization of soft tissues: Kaupia, 2:99-113.

Wilby P.R., White M.A. 1995. Phosphatized soft tissues in bivalves from the Portland Roach of Dorset (Upper Jurassic). Geological Magazine, 132:117-120.

Wilby P.R., Briggs D.E.G. 1997. Taxonomic trends in the resolution of detail preserved in fossil phosphatized soft tissue. Geobios, 20:493-502.

Wilby P.R., Briggs D.E.G., Bernier P. \& Gaillard C. 1996. Role of microbial mats in the fossilization of soft tissues. Geology, 24:787-790. 